\title{
Auditory Thalamus, Dorsal Hippocampus, Basolateral Amygdala, and Perirhinal Cortex Role in the Consolidation of Conditioned Freezing to Context and to Acoustic Conditioned Stimulus in the Rat
}

\author{
Benedetto Sacchetti, Carlo Ambrogi Lorenzini, Elisabetta Baldi, Giovanna Tassoni, and Corrado Bucherelli \\ Dipartimento di Scienze Fisiologiche, Viale G.B. Morgagni 63, I-50134 Florence, Italy
}

On the basis of previous experimental evidence, it is known that the auditory thalamus (AT), the dorsal hippocampus (DH), the basolateral amygdala (BLA), and the perirhinal cortex (PC) are involved in the mnemonic processing of conditioned freezing. In particular, BLA and PC appear to be involved both in conditioned stimulus (CS) and context conditioned freezing. Through AT, the auditory CS is sent to other sites, whereas DH is involved in context conditioning. Nevertheless, the existing evidence does not make it possible to assess AT, DH, BLA, and $\mathrm{PC}$ involvement during the consolidation phase of conditioned freezing. To address this question, fully reversible tetrodotoxin (TTX) inactivation was performed on adult male Wistar rats having undergone CS and context fear training. Anesthetized animals were injected stereotaxically with TTX (either 5 or $10 \mathrm{ng}$ in 0.5 or $1.0 \mu \mathrm{l}$ of saline, according to site dimensions) at increasing post-acquisition delays. Context and CS freezing durations were measured during retention testing, always performed 48 and $72 \mathrm{hr}$ after TTX administration. The results showed that AT inactivation does not disrupt consolidation of either contextual or auditory fear memories. In contrast, inactivation of the other three structures disrupted consolidation. For the $\mathrm{DH}$, this disruption was specific to contextual cues and only occurred when inactivation was performed early (up to 1.5 hr) after training. The BLA and PC were shown to be involved in the consolidation of both contextual and auditory fear. Their involvement persisted for longer periods of time (2 d for BLA and $8 \mathrm{~d}$ for $\mathrm{PC}$ ). These findings provide information to build a temporal profile for the post-training processing of fear memories in structures known to be important for this form of learning. The results are discussed in relation to previous studies on conditioned freezing and other aversive conditioned response neural correlates.

Key words: reversible tetrodotoxin inactivation; CS and context freezing; consolidation; auditory thalamus; dorsal hippocampus; basolateral amygdala; perirhinal cortex
In pavlovian fear conditioning, the unconditioned stimulus (US), e.g., electrical footshocks, becomes associated not only with an appropriate conditioned stimulus (CS) but also with the environment in which the punishment is administered, i.e., the training context. This means that the conditioned subjects, for instance rats, will exhibit significant conditioned fear to both CS and context. Their fear may be conveniently and separately measured as conditioned freezing duration (Kim and Fanselow, 1992; Rudy and Morledge, 1994; Oler and Markus, 1998; Sacchetti et al., 1999).

When an acoustic CS is used in fear conditioning, several neural sites are thought to be involved in conditioned freezing learning: the auditory thalamus (AT), primarily involved in acoustic input processing (LeDoux et al., 1983, 1986; Romanski and LeDoux, 1992), the dorsal hippocampus (DH), involved in context conditioning (Kim and Fanselow, 1992; Phillips and LeDoux, 1992; Rudy and Morledge, 1994; Maren, 1998), the basolateral amygdala (BLA) (Phillips and LeDoux, 1992; Maren and Fanselow, 1995, 1996; Maren et al., 1996; Muller et al., 1997), and the perirhinal cortex (PC) (Corodimas and LeDoux, 1995; Su-

Received April 30, 1999; revised July 21, 1999; accepted Aug. 11, 1999.

We thank A. Aiazzi, S. Cammarata, M. Dolfi, and A. Vannucchi for their technical assistance.

Correspondence should be addressed to Prof. Corrado Bucherelli, Dipartimento di Scienze Fisiologiche, Viale G. B. Morgani 63, I-50134 Florence, Italy. E-mail: ambuc@cesit1.unifi.it.

Copyright (C) 1999 Society for Neuroscience 0270-6474/99/199570-09\$05.00/0 zuki, 1996), the latter two playing a role in CS and context conditioning. These functional attributions are based almost exclusively on irreversible lesions results. The irreversible lesion technique does not make it possible to define in which of the putative phases of mnemonic processing (acquisition, consolidation, or storage-retrieval) a given site plays an active role (Bures and Buresova, 1990). Other, and possibly more exhaustive, information can be obtained by means of the reversible inactivation technique. This technique makes it possible to reversibly inactivate a given neural site during any of the putative mnemonic phases without interfering with the other ones, thus defining the mnemonic role of a given site phase by phase (McGaugh, 1966; Bures and Buresova, 1990; Ambrogi Lorenzini et al., 1997, 1998a, 1999).

Concerning the conditioned freezing responses, of the above mentioned sites only BLA has been investigated by means of the reversible inactivation technique and this only during acquisition and retrieval (Helmstetter, 1992; Fanselow and Kim, 1994; Muller et al., 1997). Therefore, it appears that, as of now, not much is known about the role played by AT, DH, BLA, and PC in fear mnemonic processing taking place between acquisition and retrieval, i.e., during consolidation, when the engram is modified from a short-term one to a long-term one, to be subsequently stored (McGaugh, 1966; Dudai, 1996; Nadel and Moscovich, 1997).

The aim of the present work is to obtain information on 
consolidation processing of CS and context conditioned freezing. As stated above, the reversible inactivation performed in this mnemonic phase makes it possible to evaluate the role of a chosen structure in conditioned freezing consolidation without interfering with either antecedent (acquisition) or subsequent (storage and/or retrieval) phases. AT, DH, BLA, and PC are reversibly inactivated bilaterally by means of the stereotaxic administration of tetrodotoxin (TTX) performed at increasing post-acquisition delays in rats having undergone fear conditioning to an acoustic $\mathrm{CS}$ and to the context. In this way, it is possible to follow the chronological evolution of CS and context engram consolidative processing to address the question of whether or not both follow the same neural and chronological pattern.

\section{MATERIALS AND METHODS}

\section{Animals}

Seventy-day-old male albino Wistar rats (average body weight of $290 \mathrm{gm}$ ) (Morini, S. Polo D'Enza, Italy) were used. The animals were individually housed in stainless steel cages in a room with a natural light/dark cycle and constant temperature of $20 \pm 1^{\circ} \mathrm{C}$. The rats had access to food and water ad libitum throughout the experiment. All animal care and experimental procedures were conducted in accordance with the Italian legislation and the official regulations of the European Communities Council on use of laboratory animals (Directive of November 24, 1986; 86/609/EEC).

\section{Behavioral procedures}

Apparatus. A basic Skinner box module (Modular Operant Cage; Coulbourn Instruments, Allentown, PA) was used to induce freezing. Box dimensions were $29 \times 31 \times 26 \mathrm{~cm}$. The top and two opposite sides were made of aluminum panels. The other two sides were made of transparent plastic. The floor was made of stainless steel rods connected to a shock delivery apparatus (Grid Floor Shocker, model E13-08; Coulbourn Instruments Inc.). There was a loudspeaker to emit acoustic stimuli of known intensity, frequency, and duration. The apparatus was connected to a stimulus programming device (Scatola di comando Arco 2340; Ugo Basile) to predetermine number, duration, and rate of CS-US couplings. The apparatus was placed in an acoustically insulated room $(3.5 \times 1.8 \times$ $2.1 \mathrm{~m})$, kept at a constant temperature of $20 \pm 1^{\circ} \mathrm{C}$. Illumination inside the room was 60 lux.

Context freezing response was measured in the same apparatus that had been used for conditioning. Freezing response to explicit CS (sound) was measured in a totally different apparatus from that used for conditioning. The apparatus was a modified shuttle box apparatus (Ugo Basile) $(20 \times 47 \times 20 \mathrm{~cm})$. The walls were made of gray opaque plastic with black vertical stripes (width of $1 \mathrm{~cm}$, spaced $3 \mathrm{~cm}$ apart). The lid was made of transparent plastic and the floor of black opaque plastic. In the apparatus, there was a loudspeaker to administer acoustic stimuli to the experimental subjects. The apparatus was connected to a stimulus programming unit (Automatic Reflex Conditioner 7501; Ugo Basile) to predetermine CS (number of stimuli, duration of stimuli, and rate of stimulation). The unit could also predetermine intensity and frequency of the acoustic stimulus. The apparatus was placed in an acoustically insulated room $(3.5 \times 3.6 \times 2.1 \mathrm{~m}) \mathrm{kept}$ at a constant temperature of $20 \pm 1^{\circ} \mathrm{C}$. Illumination inside the room was 10 lux.

Conditioning. On day 1 , the rat was gently taken manually from the home cage, placed in a bucket, and carried from the housing room to the appropriate soundproofed room. Once there, it was placed inside the conditioning apparatus. The rat was left undisturbed for $3 \mathrm{~min}$. After this time, CS as an $800 \mathrm{~Hz}$ tone from a frequency generator, amplified to 75 dB (Phillips and LeDoux, 1992; Sacchetti et al., 1999) lasting 6 sec was administered seven times, at $30 \mathrm{sec}$ intervals. The last $1 \mathrm{sec}$ of each CS was paired with the US as electric footshock. US intensity was $0.5 \mathrm{~mA}$, as in previous experiments (Sacchetti et al., 1999). Two minutes after the end of the stimulation pattern, the rats were brought back to the home cage.

Conditioned freezing measurement. Freezing duration was measured 48 and $72 \mathrm{hr}$ after TTX or saline administration. To measure contextual freezing, the animals were again placed inside the conditioning apparatus and left there for $3 \mathrm{~min}$. While they were there, neither electrical nor acoustic stimuli were administered. After that time, they were brought back to the home cage. Rats' behavior was recorded by means of a closed circuit television system. To measure CS freezing, the animals were placed in the other apparatus to avoid the facilitation of CS retention caused by contextual cues (Balaz et al., 1982; Corodimas and LeDoux, 1995; Oler and Markus, 1998). Once inside the apparatus, the animal was left undisturbed for $3 \mathrm{~min}$. After this time, during a subsequent second 3 min period, a series of seven acoustic stimuli was administered, identical to those used during the conditioning session (frequency, intensity, duration, and intervals between stimuli). By means of a closed circuit television system, rats' behavior was recorded for the entire 6 min period, after which the animals were brought back to the home cage. Rats of each group were divided in two subgroups (four to six animals). As in previous experiments (Sacchetti et al., 1999), one subgroup was tested for context freezing on the first day and for CS freezing the day after, whereas the other followed a specular schedule (context, first day; CS, second day). This schedule was used to ensure that the exposure of all the subjects first to context and secondly to CS, or vice versa, would not bias the retention of the two responses (Winocur, 1997).

Freezing (immobility) was defined as the complete absence of somatic motility, respiratory movements excepted (LeDoux et al., 1983). Measurements were performed by means of a stopwatch by personnel that did not known to which experimental group each animal belonged. Total cumulated freezing time (i.e., total seconds spent freezing during each 3 min period) was measured.

\section{Surgery and drug administration}

Functional inactivation of the chosen structure was induced by the administration of either 5 or $10 \mathrm{ng}$ of TTX (Sigma, Milano, Italy), dissolved in 0.5 or $1.0 \mu \mathrm{l}$ of saline, respectively, into points with stereotaxic coordinates obtained from the atlas of Paxinos and Watson (1986). Mean inactivated nervous tissue radius after TTX administration was estimated at $1 \mathrm{~mm}$ for $10 \mathrm{ng}$ and $0.7-0.8 \mathrm{~mm}$ for $5 \mathrm{ng}$ of TTX injection (Zhuravin and Bures, 1991; Ambrogi Lorenzini et al., 1995) (Fig. 1). At least 20 min were necessary to reach maximal neural inactivation. Inactivation lasted no less than $120 \mathrm{~min}$, exponentially decreasing and disappearing completely within $24 \mathrm{hr}$ (Zhuravin and Bures, 1991). TTX was injected under general anesthesia (ketamine, $100 \mathrm{mg} / \mathrm{kg}$, i.p.) at different post-acquisition intervals for each group of animals. Rats were held in the stereotaxic apparatus. The injection needle (outside diameter, 0.3 $\mathrm{mm}$ ), connected with a short piece of polyethylene tubing to a Hamilton syringe, was fixed in the electrode holder of the stereotaxic apparatus and introduced into the target structure. Either 0.5 or $1.0 \mu \mathrm{l}$ of the solution was injected over a 1-2 min period, and the needle was left in place for another 1 min before it was slowly withdrawn.

TTX was bilaterally injected in all experiments. Control group rats were injected bilaterally with saline.

\section{Detailed methods}

Shocked and not shocked control animals. Two control groups of animals not submitted to surgery (eight rats in each group) underwent the same conditioning procedure, one receiving the electric footshocks and the other not receiving the electric footshocks. Retention testing was performed 4 and $5 \mathrm{~d}$ after acquisition trial.

Post-acquisition AT inactivation. AT functional inactivation was induced by injection of $5 \mathrm{ng}$ of TTX into points with the following stereotaxic coordinates: anteroposterior (AP), -5.6; lateral (L), 3.3; and ventral (V), 5.8 according to Paxinos and Watson (1986) (Figs. 1, 2). Different groups of animals were injected at diverse post-acquisition delays. A total of 65 rats were randomly divided into six groups: TTXinjected (T) and saline-injected (S) at three different post-acquisition delays of $0.25,1.5$, and $6 \mathrm{hr}$. Because of inadequate morphological evidence, 10 animals were excluded. The remaining 55 animals made up the following groups, each group ranging between 8 and 11 animals: $\mathrm{T}-0.25, \mathrm{~S}-0.25, \mathrm{~T}-1.5, \mathrm{~S}-1.5, \mathrm{~T}-6$, and S-6.

Post-acquisition DH inactivation. As described previously (Ambrogi Lorenzini et al., 1996), DH functional inactivation was induced by the injection of $10 \mathrm{ng}$ of TTX into points with the following stereotaxic coordinates: AP, $-4.1 ; \mathrm{L}, \pm 2.5$; and $\mathrm{V}, 3.1$ according to Paxinos and Watson (1986) (Figs. 1, 2). Different groups of animals were injected at diverse post-acquisition delays. A total of 84 rats were randomly divided into eight groups: TTX-injected and saline-injected at four different post-acquisition delays of $0.25,1.5,6$, and $24 \mathrm{hr}$. Because of inadequate morphological evidence, 12 animals were excluded. The remaining 72 animals made up the following groups, each group ranging between 8 and 11 animals: T-0.25, S-0.25, T-1.5, S-1.5, T-6, S-6, T-24, and S-24.

Post-acquisition BLA inactivation. BLA functional inactivation was induced by the injection of $5 \mathrm{ng}$ of TTX into points with the following 
PC

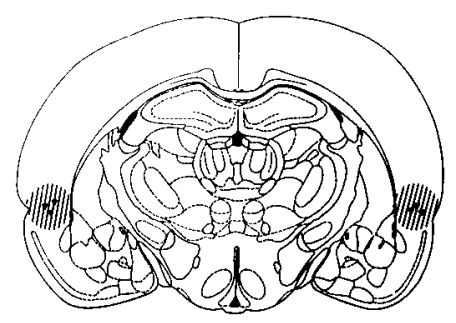

Bregma $-2.56 \mathrm{~mm}$

Bregma -3.14 mm

\section{Bregma $-4.16 \mathrm{~mm}$}

Bregma $-5.60 \mathrm{~mm}$

Figure 1. Extension of TTX inactivation of PC, BLA, DH, and AT, estimated on the basis of injection sites ( $\boldsymbol{\nabla}$, end of needle tracks) and on known characteristics of TTX diffusion (see Materials and Methods). Plates adapted from the atlas of Paxinos and Watson (1986).

stereotaxic coordinates: AP, $-3 ; \mathrm{L}, \pm 4.8$; and $\mathrm{V}, 8.7$ according to Paxinos and Watson (1986) (Figs. 1, 2). Different groups of animals were injected at diverse post-acquisition delays. A total of 141 rats were randomly divided into 14 groups: TTX-injected and saline-injected at seven different post-acquisition delays of $0.25,1.5,6,24,48,96$, and 192 hr. Because of inadequate morphological evidence, 14 animals were excluded. The remaining 127 animals made up the following groups, each group ranging between 8 and 11 animals: T-0.25, S- $0.25, \mathrm{~T}-1.5, \mathrm{~S}-1.5, \mathrm{~T}-6$, S-6, T-24, S-24, T-48, S-48, T-96, S-96, T-192, and S-192.

Post-acquisition PC inactivation. As described previously (Ambrogi Lorenzini et al., 1998b), partial PC functional inactivation, centered between anterior and posterior PC limits, was induced by injection of 5 ng of TTX into points with the following stereotaxic coordinates: AP, -2.6 ; L, \pm 6.1 ; and V, 7 according to Paxinos and Watson (1986) (Figs. $1,2)$. Different groups of animals were injected at diverse postacquisition delays. A total of 158 rats were randomly divided into 16 groups: TTX-injected and saline-injected at eight different postacquisition delays of $0.25,1.5,6,24,48,96,192$, and $384 \mathrm{hr}$. Because of inadequate morphological evidence, 18 animals were excluded. The remaining 140 animals made up the following groups, each group ranging between 8 and 11 animals: T-0.25, S- 0.25 , T-1.5, S-1.5, T-6, S-6, T-24, S-24, T-48, S-48, T-96, S-96, T-192, S-192, T-384, and S-384.

\section{Statistical analysis}

One-way ANOVA, mixed ANOVAs, with treatment (TTX and saline) and different post-acquisition delays as a between-subjects variable and
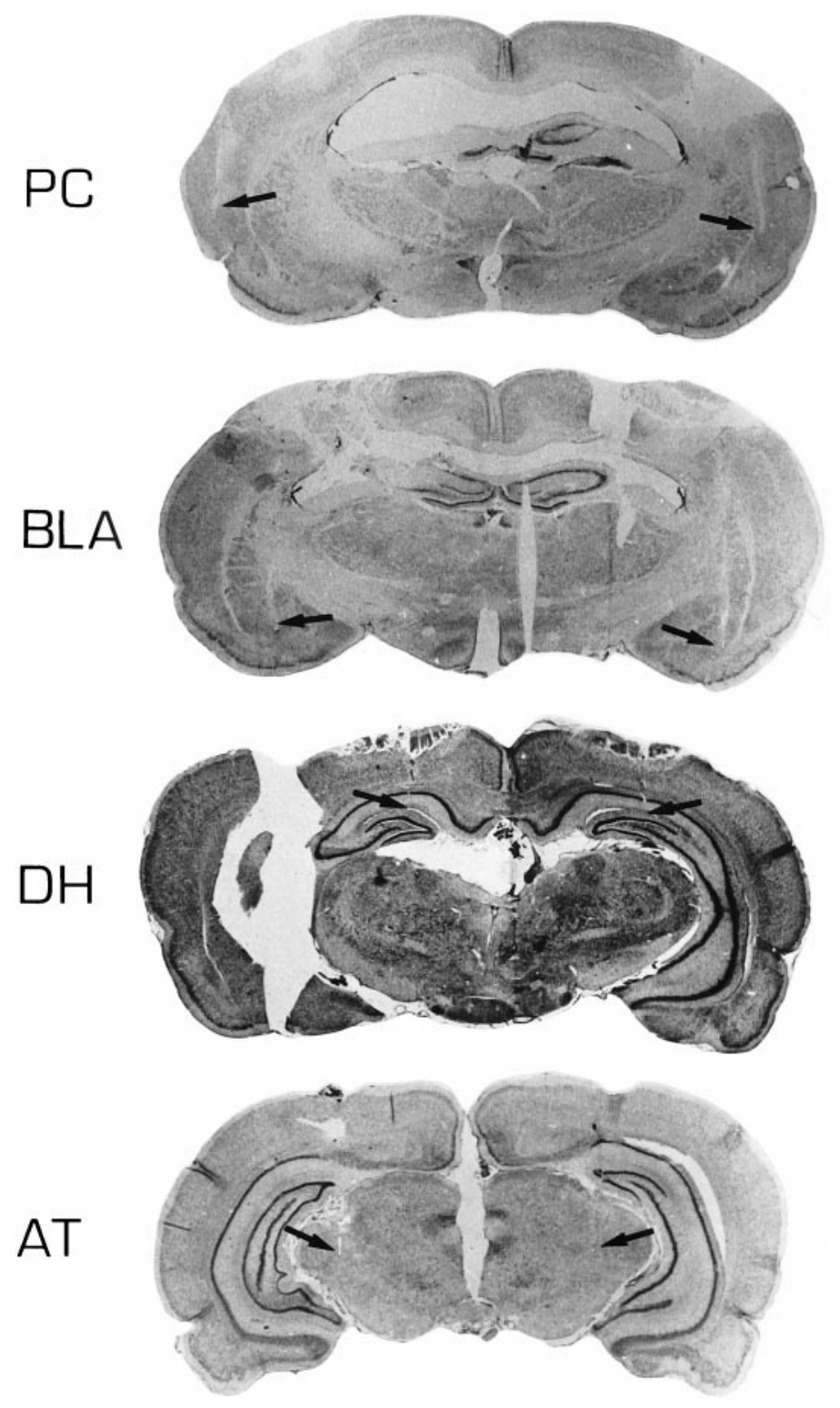

Figure 2. Photomicrographs of operated brains. The arrows indicate the end of the needle track.

context and CS freezing as a within-subjects variable, and NewmanKeuls multiple comparisons test were used.

\section{Morphology}

At the end of the experiments, injected sites were histologically verified. Rats were deeply anesthetized and intracardially perfused with saline, followed by $4 \%$ formaldehyde. Brains were cut with a freezing microtome, and injection needle tracks were identified in Nissl-stained serial sections (Fig. 2). Subjects whose histological evidence was not adequate were excluded from data processing.

\section{RESULTS}

All groups of animals were divided into two subgroups, which were respectively measured for CS or context freezing in the $2 \mathrm{~d}$ of testing (see Materials and Methods). Because there were no significant statistical differences between subgroups, it was possible to statistically elaborate the cumulated freezing results (to CS and to the context) of the first and second day, so that final statistical analysis was performed on groups of rats ranging between 8 and 12 animals. 


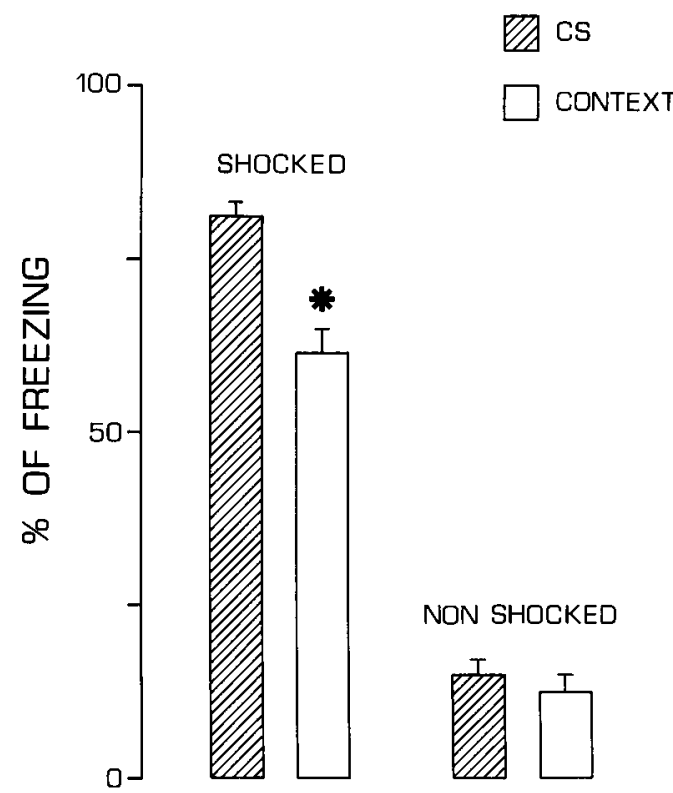

Figure 3. CS and context freezing in unoperated control (shocked and nonshocked) rat groups. Mean \pm SEM freezing as percentage of total time during retention testing in the conditioning apparatus without acoustic stimulation (context) and in the other apparatus with acoustic stimulation $(\mathrm{CS}) .{ }^{*} p<0.05$, significant statistical differences between the conditioned responses.

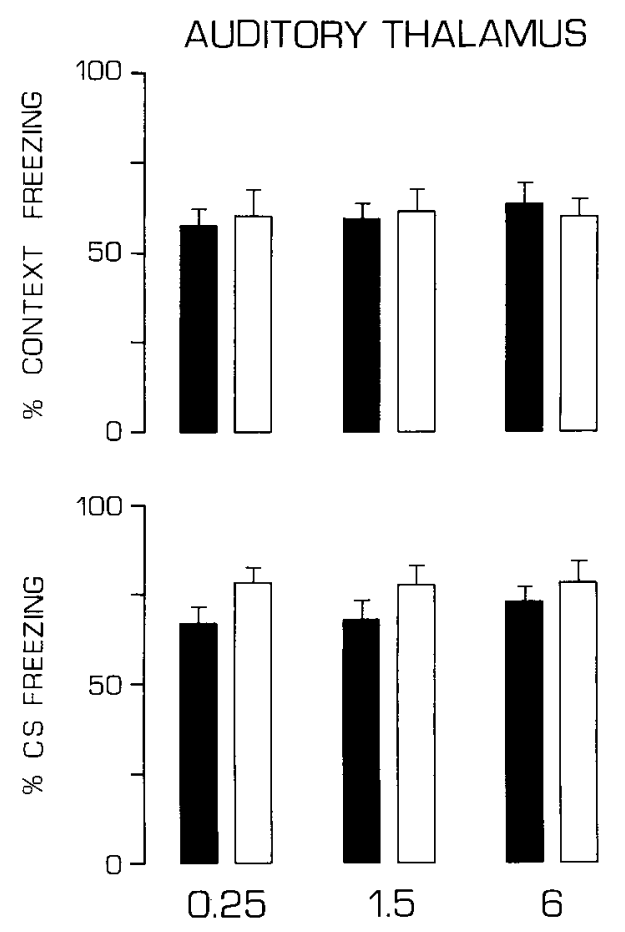

Figure 4. Effects of auditory thalamus bilateral TTX inactivation at increasing post-acquisition delays $(0.25,1.5$, and $6 \mathrm{hr})$. Black columns, TTX-injected groups. White columns, Saline-injected groups. Mean \pm SEM context and CS total freezing duration during retention testing. For explanation, see Figure 3.

\section{Control groups}

All control saline-injected groups (Figs. 3-7) showed conditioned responses quantitatively comparable with those of conditioned control unoperated groups (Fig. 3). Context and CS freezing

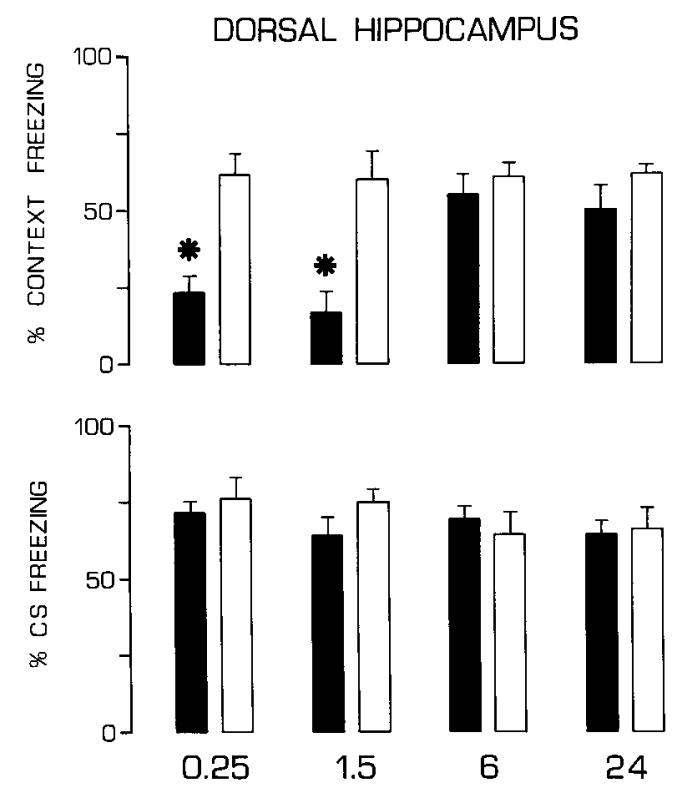

Figure 5. Effects of dorsal hippocampus bilateral TTX inactivation at increasing post-acquisition delays $(0.25,1.5,6$, and $24 \mathrm{hr}) .{ }^{*} p<0.05$, significant statistical differences between treated and respective control groups. For explanation, see Figure 4.

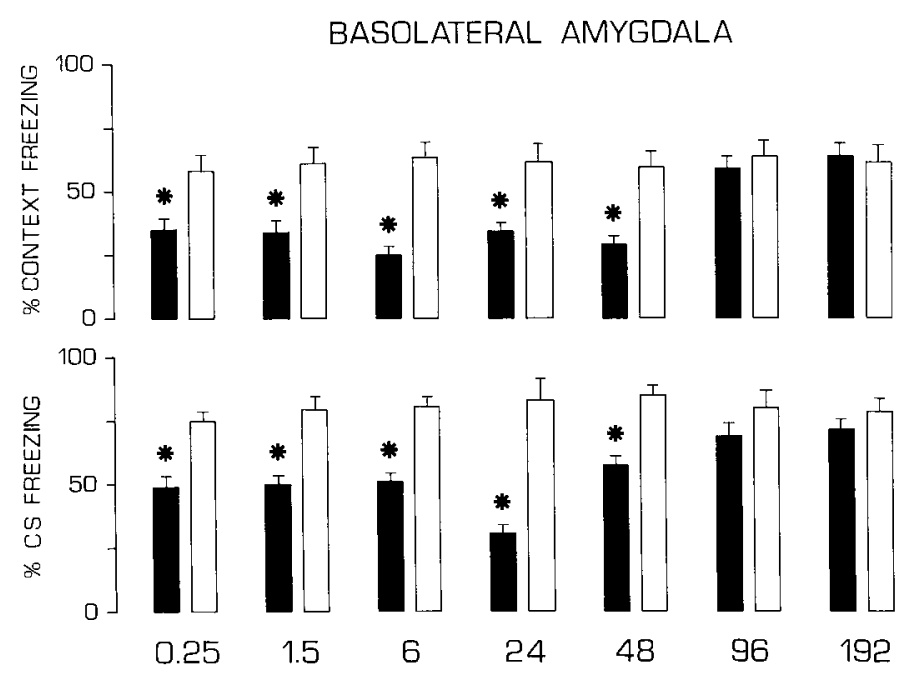

Figure 6. Effects of basolateral amygdala bilateral TTX inactivation at increasing post-acquisition delays $(0.25,1.5,6,24,48$, and $96 \mathrm{hr}) .{ }^{*} p<$ 0.05 , significant statistical differences between treated and respective control groups. For explanation, see Figure 4.

responses were well developed against the very poor response of animals not subjected to footshocks (Fig. 3) and did not significantly decrease $18 \mathrm{~d}$ after the conditioning session (PC S-384 group) (Fig. 7). In particular, CS freezing response was higher than context freezing response (Fig. 3). Mixed ANOVAs $(2 \times 2)$ showed that there were differences for different responses (CS and context) $\left(F_{(1,28)}=4.84 ; p<0.05\right)$ and for treatment (shocked and nonshocked) $\left(F_{(1,28)}=26.34 ; p<0.001\right)$. There were significant interactions between responses and treatments $\left(F_{(1,28)}=\right.$ 4.65; $p<0.05)$. Post hoc Newman-Keuls test showed that there were significant differences between $\mathrm{CS}$ and context freezing $(p<0.05)$. During the first 3 min subperiod of exposure to the new context (without CS, acoustic stimulation), the freezing 


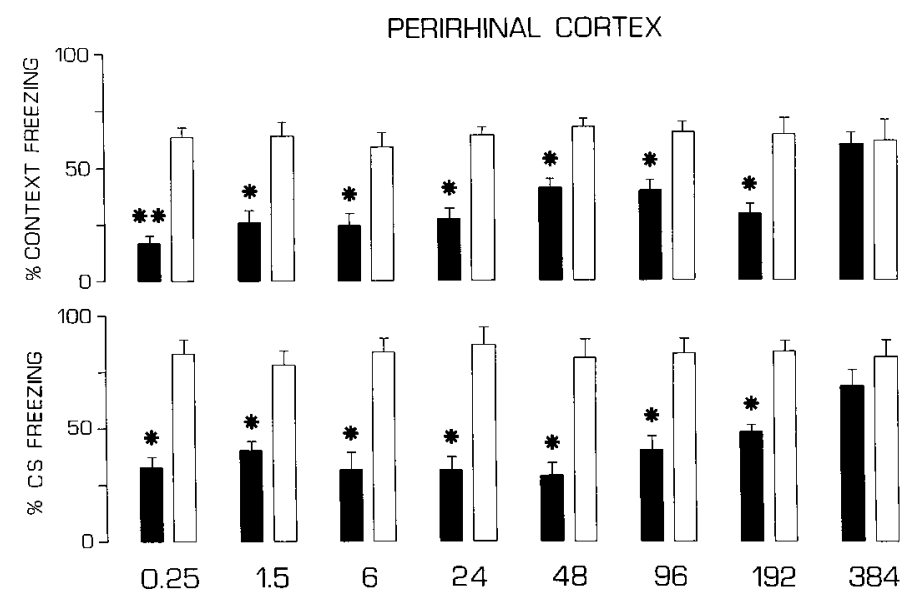

Figure 7. Effects of perirhinal cortex bilateral TTX inactivation at increasing post-acquisition delays $(0.25,1.5, .6,14,48,96,192$, and $348 \mathrm{hr})$. ${ }^{*} p<0.05, * * p<0.01$, significant statistical differences between treated and respective control groups. For explanation, see Figure 4.

response was very low in all groups of animals and comparable with that of the control group that had not received the footshocks $(12.3 \%$ freezing of total exposure time). These results show the absence of generalization phenomena and the specificity of the freezing response to the CS in this new context.

\section{Auditory thalamus}

After AT reversible inactivation at all three post-acquisition delays $(0.25,1.5$, and $6 \mathrm{hr})$, neither CS freezing nor context freezing responses were impaired (Fig. 4). Mixed ANOVAs $(2 \times$ $2 \times 3)$ showed that there were differences for different responses $\left(F_{(1,98)}=11.9 ; p<0.001\right)$ but not for treatment $\left(F_{(1,98)}=2.01\right.$; $\mathrm{NS})$ or for time lapsed from acquisition training $\left(F_{(2,98)}=0.25\right.$; NS). There were no significant interactions. In all of the six groups, freezing duration during the first $3 \mathrm{~min}$ in the new context without CS presentation ranged between 11.7 and $15.6 \%$ of total time. One-way ANOVA showed that there were no significant differences between groups $\left(F_{(5,49)}=0.62\right.$; NS $)$, thus showing that AT inactivation did not determine generalization phenomena.

\section{Dorsal hippocampus}

After DH inactivation, context freezing response was impaired up to the $1.5 \mathrm{hr}$ post-acquisition delay. On the other hand, CS freezing response was never impaired (Fig. 5). Mixed ANOVAs $(2 \times 2 \times 4)$ showed that there were differences for different responses $\left(F_{(1,129)}=23.3 ; p<0.001\right)$ and treatments $\left(F_{(1,129)}=\right.$ 12.5; $p<0.001)$ but not for time lapsed from acquisition training $\left(F_{(3,129)}=0.74 ; \mathrm{NS}\right)$. There were significant interactions between responses and treatments $\left(F_{(1,129)}=7.48 ; p<0.01\right)$, responses and intervals $\left(F_{(3,129)}=3.1 ; p<0.05\right)$, and treatments and intervals $\left(F_{(3,129)}=3.3 ; p<0.05\right)$. The post hoc Newman-Keuls test showed that there were significant differences between groups $\mathrm{T}-0.25$ and $\mathrm{T}-1.5$ and the respective control groups (S-0.25 and $\mathrm{S}-1.5) ; p<0.05$ in both cases (Fig. 5). In the eight groups, freezing duration during the first $3 \mathrm{~min}$ in the new context without CS presentation ranged between 10.4 and $14.3 \%$ of total time. Oneway ANOVA showed that there were no significant differences between groups $\left(F_{(7,64)}=0.75\right.$; NS), thus showing that $\mathrm{DH}$ inactivation did not determine generalization phenomena.

\section{Basolateral amygdala}

After BLA reversible inactivation, context and CS freezing responses were impaired up to the $48 \mathrm{hr}$ post-acquisition delay (Fig.
$6)$. Mixed ANOVAs $(2 \times 2 \times 7)$ showed that there were differences for different responses $\left(F_{(1,226)}=37.23\right.$; $\left.p<0.001\right)$, treatments $\left(F_{(1,226)}=71.34 ; p<0.001\right)$, and time lapsed from acquisition training $\left(F_{(6,226)}=3.08 ; p<0.01\right)$. There were significant interactions between time lapsed and treatments $\left(F_{(6,226)}=2.62\right.$; $p<0.05)$. The post hoc Newman-Keuls test showed that there were significant differences between T-0.25, T-1.5, T-6, T-24, and $\mathrm{T}-48$ groups and the respective controls (S) for both CS freezing response $(p<0.05$ in all instances) and context freezing response ( $p<0.05$ in all instances) (Fig. 6). In the 14 groups, freezing duration during the first $3 \mathrm{~min}$ in the new context without CS presentation ranged between 12.3 and $15.6 \%$ of total time. Oneway ANOVA showed that there were no significant differences between groups $\left(F_{(13,113)}=0.44 ; \mathrm{NS}\right)$, thus showing that BLA inactivation did not determine generalization phenomena.

\section{Perirhinal cortex}

After PC reversible inactivation, context and CS freezing responses were impaired up to the $192 \mathrm{hr}$ post-acquisition delay (Fig. 7). Mixed ANOVAs $(2 \times 2 \times 8)$ showed that there were differences for different responses $\left(F_{(1,248)}=31.14 ; p<0.001\right)$, treatments $\left(F_{(1,248)}=217.01 ; p<0.001\right)$, and time lapsed from acquisition training $\left(F_{(7,248)}=2.81 ; p<0.01\right)$. There were significant interactions between responses and treatments $\left(F_{(1,248)}=\right.$ $5.16 ; p<0.05)$ and treatments and times lapsed $\left(F_{(1,248)}=3.19\right.$; $p<0.01)$. The post hoc Newman-Keuls test showed that there were significant differences between groups T-0.25, T-1.5, T-6, $\mathrm{T}-24, \mathrm{~T}-48, \mathrm{~T}-96$, and T-192 and the respective control groups (S) both for context freezing $(p<0.01$ at 0.25 ; $p<0.05$ in all other instances) and CS freezing ( $p<0.05$ in all instances) (Fig. 7). In the 16 groups, freezing duration during the first $3 \mathrm{~min}$ in the new context without CS presentation ranged between 13.4 and $16.7 \%$ of total time. One-way ANOVA showed that there were no significant differences between groups $\left(F_{(15,124)}=0.71\right.$; NS), thus showing that PC inactivation did not determine generalization phenomena.

\section{DISCUSSION}

After the single session acquisition paradigm, all control groups (operated and unoperated) exhibited very good conditioned freezing responses to both $\mathrm{CS}$ and context, the former being stronger than the latter (Fig. 3) (Phillips and LeDoux, 1992; Sacchetti et al., 1999). The fact that unoperated groups (Fig. 3) and control groups subjected to general anesthesia and injected saline (Figs. 4-7) exhibited quite similar responses once more confirms that post-trial anesthesia does not influence retention (Ambrogi Lorenzini et al., 1996, 1997). The present results confirm the effectiveness of the single-trial paradigm used, the 0.5 $\mathrm{mA}$ footshock intensity being sufficient to condition the subjects (Sacchetti et al., 1999). The present results are well comparable with previous ones obtained using conditioning paradigms quite similar to those presently used. It has been reported, in fact, that experimental subjects exhibit good and robust CS and context fear conditioning lasting for months (Oler and Markus, 1998). Moreover, the short total freezing duration during the first $3 \mathrm{~min}$ subperiod (new context) exhibited by all control groups shows that this paradigm did not induce generalization phenomena (Sacchetti et al., 1999). This result shows that the separately measured freezing responses are directly related to either one of the two specific mnemonic traces (CS and context), other factors, if any, being negligible (Kim and Fanselow, 1992; Sacchetti et al., 1999). 
Indeed, a single acquisition session paradigm is the necessary prerequisite for the investigation of the chronological evolution of the involvement of a given neural structure in engram consolidation. In fact, in multitrial acquisition paradigms, it is impossible to define the subsequent mnemonic phases temporally, i.e., to determine exactly when consolidation begins (Bures and Buresova, 1990; Ambrogi Lorenzini et al., 1997). To ascertain consolidation chronology, reversible TTX inactivations were performed at increasing post-acquisition delays. Retention testing was always performed $48 \mathrm{hr}$ after TTX administration. This schedule ensures that the several investigated neuronal sites were inactivated only during consolidation, without interfering with acquisition (the inactivation was performed after acquisition) or retrieval; retention testing was always performed when there were no residual TTX effects (Zhuravin and Bures, 1991). Moreover, we must bear in mind that DH, BLA, and PC support some spontaneous behaviors. In fact $\mathrm{DH}$, controls unconditioned freezing (Blanchard et al., 1970; Blanchard and Blanchard, 1972b; McNish et al., 1997), BLA supports unconditioned freezing (Blanchard and Blanchard, 1972a; Davis, 1992), and PC controls spontaneous startle reactions (Rosen et al., 1992). This means that the functional absence of these structures during retrieval testing may have the same effect on unconditioned aversive behaviors; therefore, there could be some unwanted interference with the observable freezing response. On the other hand, AT being a crucial pathway for auditory input distribution (LeDoux et al., 1985, 1987) its inactivation makes it impossible for the acoustic information to reach the relevant sites. In the present experimental design, AT, DH, BLA, and PC were selectively inactivated only during the post-acquisition phase (to selectively study the consolidation of CS and/or context memory traces), thus avoiding possible masking effects.

On the basis of administration site accuracy and TTX diff usion radius estimation (see Materials and Methods), it can be stated that TTX inactivated the chosen sites selectively, without significantly affecting adjacent brain structures (Figs. 1, 2). Indeed, the different chronological involvement of the investigated neural sites in memorization processing indicates that the observed effects of TTX inactivation are not attributable to a nonspecific and diff use alteration of cerebral function but are directly related to the inactivation of distinct neural structures. The absence of generalization phenomena in all TTX-injected groups shows that the intracerebral administration of this compound does not induce behavioral modifications and/or illness that may cause generalized aversion.

The present results show that, during consolidation, AT is not necessary for the mnemonic processing of CS and context freezing responses. Because TTX inactivated the whole site, the lack of amnesic effects cannot be imputed to its partial inactivation (Fig. 1 ). Good context response retention confirms that AT is not necessary to memorize nonauditory inputs (LeDoux et al., 1986). On the other hand, it has been reported that AT irreversible lesions, performed in either pre-acquisition (LeDoux et al., 1983, 1986; Romanski and LeDoux, 1992) or post-acquisition (Jarrell et al., 1986), were followed by amnesia specific to an acoustic CS. The present findings show that these effects cannot be caused by the absence of AT activity during consolidation. Rather, the reported amnesia could be caused by the exclusion of AT during acquisition and/or retrieval. In fact, it has been repeatedly stated that AT is involved in both the transmission of sensory inputs to neocortical areas (e.g., auditory cortex, PC) (LeDoux et al., 1983, 1985; Romanski and LeDoux, 1992), as well as to other subcor- tical structures (amygdala) (LeDoux et al., 1983, 1985; Romanski and LeDoux, 1992), and CS-US association (Cruikshank et al., 1992; McEchron et al., 1995). If this is true, AT may be of importance as an acoustic stimuli (CS) relay station toward subcortical and cortical structures, possibly for CS-US coupling, but not for the subsequent consolidation process. It may be underlined that this conclusion could not be reached on the basis of irreversible lesions results.

The present findings not only confirm that $\mathrm{DH}$ is involved in contextual and not in CS memorization (Black et al., 1977; Kim and Fanselow, 1992; Phillips and LeDoux, 1992; Oler and Markus, 1998) but precisely define DH temporal involvement in contextual consolidation, the site being necessary only in the early period of this memorization phase. In contrast, BLA is necessary for both $\mathrm{CS}$ and context freezing response consolidation up to $2 \mathrm{~d}$ after acquisition. As far as we know, BLA involvement in the consolidation of conditioned freezing responses has never been reported before. Previously, BLA reversible inactivation was performed only during acquisition (Helmstetter, 1992; Fanselow and Kim, 1994; Muller et al., 1997) or retrieval (Helmstetter, 1992; Muller et al., 1997). In these mnemonic phases, BLA was found to be necessary for both CS and context learning (Helmstetter, 1992; Fanselow and Kim, 1994; Muller et al., 1997). Partial PC reversible inactivation disrupts fear conditioning consolidation. PC inactivation shows that this site is necessary for both CS and context fear response learning, up to $8 \mathrm{~d}$ after acquisition. The present results provide the chronological quantification of PC involvement besides confirming previous qualitative findings; when PC was irreversibly damaged some days after the acquisition session, amnesia specific to acoustic CS freezing (Corodimas and LeDoux, 1995), context freezing (Corodimas and LeDoux, 1995), and CS startle response (Rosen et al., 1992; Campeau and Davis, 1995) was observed.

Thus, an early period (up to $1.5 \mathrm{hr}$ ) of freezing response consolidation may be defined. In it, DH, BLA, and PC all appear to be necessary for contextual learning processing, and BLA and PC both appear to be necessary to learn the response to an acoustic CS. During the following $2 \mathrm{~d}$, BLA and PC are equally necessary for the memorization of both responses. In the last and longer lasting period of consolidation (up to $8 \mathrm{~d}$ ), only PC appears to be necessary for the memorization of both responses. This may suggest that, during early consolidation, each site critically processes a particular component (facet) of the engrams. In other words, during early consolidation, CS and context engram elaboration may not be a sequential process, migrating from one site to another (e.g., CS from BLA to PC; context from DH to BLA and finally to $\mathrm{PC}$ ), but rather a complex process requiring the simultaneous participation of DH, BLA, and PC. We may recall that, by means of irreversible lesion techniques, DH and BLA were shown to be involved in fear conditioning memory processing for days and weeks after acquisition (Kim and Fanselow, 1992; Maren et al., 1996; Frankland et al., 1998; Maren, 1998). Moreover, it was reported that irreversible hippocampal damage is followed by place memory impairment. The impairment became progressively less severe with the increase of the delay between the acquisition trial and the irreversible damage (from 1 to 12 weeks). From these results, a progressive involvement of cortical areas in place memory was inferred (Sutherland et al., 1987). Possibly, all these results were attributable to some interference with storage and/or retrieval processes rather than with elaborative and consolidative ones. This contention is based on the present results; if TTX was administered at post-acquisition 
delays longer than a few hours (DH) or a few days (BLA), memory disruption was not observed.

It has been stated that no less than $6 \mathrm{hr}$ are necessary to build an adequate contextual representation (Rudy and Morledge, 1994). DH appears to be actively involved in the period during which the diverse sensorial inputs must be integrated to compose the coherent representation of the training environment. For subsequent long-term consolidation and memorization, $\mathrm{DH}$ would no longer be necessary. Indeed, the short DH context involvement duration throws doubt on the hypothesis that $\mathrm{DH}$ is necessary for context representation storage, in accord with previous statements (Otto et al., 1997). On this point, we may also recall that, in rats, a modification of electrical hippocampal activity (EPSP, population spike) was observed after exposure to new surroundings; the modification began during training and disappeared after 1 or $2 \mathrm{hr}$ (Green et al., 1990). On the other hand, electrophysiological results obtained both in vitro (McKernan and Shinnick-Gallagher, 1997) and in vivo (Rogan et al., 1997) have shown that, after acquisition, there are in the BLA long-lasting modifications of electrical activity believed to be related to CS-US coupling. The longer BLA and PC involvement (days and not hours) may also indicate that these structures are involved in the storage of both contextual representation and CS-US association, as suggested previously (Davis, 1992; Corodimas and LeDoux, 1995; Maren and Fanselow, 1996; Maren et al., 1996; Rogan et al., 1997; Maren, 1998). In particular, the longer PC involvement may mean that, during the late period of consolidation, the information processed by $\mathrm{DH}$ and BLA may go to PC, this last being the site involved for the longest time in the elaboration of both engrams. This hypothesis is in concordance with previous statements, i.e., that PC is "involved in cortical storage of information acquired through various systems, including the explicit or declarative memory system of the hippocampal formation and the emotional memory system involving the amygdala" (Corodimas and LeDoux, 1995). In fact, CS and context fear conditioning need a consolidation phase lasting several days. If a long duration could have been surmised for context conditioning, it appears less easily understandable for CS learning. Context conditioning is based on several sensory inputs, which have to be associated and integrated to build a complex, interrelated representation, requiring an elaboration that may indeed last hours and even days (Rudy and Morledge, 1994). Conversely, the association process involving a single sensorial input, the CS, and the US, could be assumed to be simpler and shorter lasting. On the contrary, the present findings show that this association process is still going on several days later. Concerning the chronological evolution of the two engrams, the finding that $\mathrm{DH}$ integrity is necessary only for the context engram suggests that $\mathrm{CS}$ and context engrams may be separately processed. On the other hand, at all the longest post-acquisition delays, the two engrams appear to be still actively processed together, following a similar chronological pattern in BLA and PC. Maybe the two engrams are processed in parallel and are eventually coupled in a complete and integrated representation of the aversive event.

Some considerations on the functional relationships between DH, BLA, and PC may be presented. Regarding PC and DH, both sites were found to be involved in context response consolidation, PC being involved much longer than DH. Moreover, it was shown that PC, but not $\mathrm{DH}$, is also involved in CS freezing response consolidation. These data may mean that $\mathrm{PC}$ is not simply a connecting route between $\mathrm{DH}$ and neocortex but plays an autonomous role. In this connection, it may be underlined that
$\mathrm{DH}$ and PC were found to be differentially involved in the learning process of other experimental paradigms. For instance, $\mathrm{DH}$ and $\mathrm{PC}$ were found to be involved in spatial paradigm learning (Black et al., 1977; Morris et al., 1986; Wiig and Bilkey, 1995; Suzuki, 1996; Ennaceur and Aggleton, 1997; Otto et al., 1997; Liu and Bilkey, 1998), but in the same paradigms, it was shown that PC is involved also in nonspatial information learning (Ennaceur and Aggleton, 1997; Wiig and Bilkey, 1995), whereas DH is not (Black et al., 1977; Morris et al., 1986; Wiig and Bilkey, 1995). If we bear in mind that contextual learning is often considered as an elementary type of spatial learning (Black et al., 1977; Nadel and Willner, 1980), the present findings on DH and PC involvement in conditioned fear learning are coherent with previous results obtained when spatial and nonspatial tasks were to be learned. Regarding BLA and PC, it cannot be excluded that $\mathrm{PC}$ acts as a connecting relay between amygdala and neocortex, as proposed previously (Rosen et al., 1992; Campeau and Davis, 1995), but it appears likely that the PC role in late consolidation may be distinct from, and independent from, that of BLA. It may be underlined that, although it is generally accepted that in fear conditioning paradigms BLA plays a key role (Davis, 1992; Maren and Fanselow, 1996; Maren et al., 1996; Maren, 1998), the present findings show that, within consolidation, $\mathrm{PC}$ is at least equally important. The present $\mathrm{PC}$ characterization is of interest because only very few experimental reports on the respective and related functions of BLA and $\mathrm{PC}$ are available and because so far the functional importance of PC had been assessed using experimental paradigms in which BLA did not appear to play a significant role (delayed nonmatching to sample, object retention, and concurrent discrimination) (Zola-Morgan et al., 1989; Meunier et al., 1993; Gaffan, 1994; Wiig and Bilkey, 1994; Suzuki, 1996).

The roles of DH, BLA, and PC have been investigated in the learning of another aversive conditioned response, the passive avoidance response (PAR). It has been shown that DH and BLA are involved in PAR consolidation up to $1.5 \mathrm{hr}$ after acquisition (Bucherelli et al., 1992; Parent and McGaugh, 1994; Ambrogi Lorenzini et al., 1996) and PC up to $8 \mathrm{~d}$ after acquisition (Ambrogi Lorenzini et al., 1998b). There is an evident similarity between the temporal involvement of $\mathrm{DH}$ and PC during the consolidation phase of conditioned freezing and PAR. This similarity may suggest that, in aversive learning, these two structures play a role that is not so much qualitatively related to the response to be learned as functionally constant. On the other hand, BLA is differently involved in PAR and freezing consolidation. It has been surmised repeatedly that the function of BLA is quite strictly related to the emotive characteristics of the used paradigms (Davis, 1992; McGaugh et al., 1995; Maren and Fanselow, 1996). It could very well be that this functional specificity explains the diverse findings (Davis, 1992; McGaugh et al., 1995; Maren and Fanselow, 1996; Maren, 1998). In fact, although fear conditioning and PAR may seem to be superficially similar, on the contrary they appear to activate or require quite different neural mechanisms. In particular, in the PAR paradigm, the avoidability of US may influence the emotive involvement of the animal and consequently cause an unequal BLA involvement. In fact, it has been proposed that BLA is necessary for the storage of fear conditioning (Davis, 1992; Maren and Fanselow, 1996; Maren et al., 1996; Maren, 1998) but not for PAR storage (McGaugh et al., 1995, 1996). On this point, the shorter temporal involvement of BLA in consolidation for PAR (Bucherelli et al., 1992) than for fear conditioning could reflect its different role in the storage process. 


\section{REFERENCES}

Ambrogi Lorenzini CG, Baldi E, Bucherelli C, Tassoni G (1995) Timedependent deficits of rat's memory consolidation induced by tetrodotoxin injections into the caudate-putamen, nucleus accumbens and globus pallidus. Neurobiol Learn Mem 63:87-93.

Ambrogi Lorenzini C, Baldi E, Bucherelli C, Sacchetti B, Tassoni G (1996) Role of dorsal hippocampus in acquisition, consolidation and retrieval of rat's passive avoidance response: a tetrodotoxin functional inactivation study. Brain Res 730:32-39.

Ambrogi Lorenzini CG, Baldi E, Bucherelli C, Sacchetti B, Tassoni G (1997) Analysis of mnemonic processing by means of totally reversible neural inactivations. Brain Res Brain Res Protoc 1:391-398.

Ambrogi Lorenzini CG, Baldi E, Bucherelli C, Sacchetti B, Tassoni G (1998a) Temporal characterization of subcortical nuclei in mnemonic processes: results of tetrodotoxin reversible inactivation studies in the rat. Arch Ital Biol 136:279-296.

Ambrogi Lorenzini C, Baldi E, Bucherelli C, Sacchetti B, Tassoni G (1998b) Perirhinal cortex role in rat's passive avoidance memorization. Eur J Neurosci 10:56-67.

Ambrogi Lorenzini CG, Baldi E, Bucherelli C, Sacchetti B, Tassoni G (1999) Neural topography and chronology of memory consolidation: a review of functional inactivation findings. Neurobiol Learn Mem 71:1-18.

Balaz MA, Capra S, Kasprow WJ, Miller RR (1982) Latent inhibition of the conditioning context: further evidence of contextual potentiation of retrieval in the absence of appreciable context-US associations. Anim Learn Behav 10:242-248.

Black AH, Nadel L, O'Keefe J (1977) Hippocampal function in avoidance learning and punishment. Psychol Bull 84:1107-1129.

Blanchard DC, Blanchard RJ (1972a) Innate and conditioned reactions to threat in rats with amygdaloid lesions. J Comp Physiol Psychol 81:281-290.

Blanchard RJ, Blanchard DC (1972b) Effects of hippocampal lesions on the rat's reaction to a cat. J Comp Physiol Psychol 78:77-82.

Blanchard RJ, Blanchard DC, Fial RA (1970) Hippocampal lesions in rats and their effect on activity, avoidance, and aggression. J Comp Physiol Psychol 71:92-102.

Bucherelli C, Tassoni G, Bures J (1992) Time-dependent disruption of passive avoidance acquisition by post-training intra-amygdala injection of tetrodotoxin in rats. Neurosci Lett 140:231-234.

Bures J, Buresova O (1990) Reversible lesions allow reinterpretation of system level studies of brain mechanisms of behavior. Concepts Neurosci 1:69-89.

Campeau S, Davis M (1995) Involvement of subcortical and cortical afferents to the lateral nucleus of the amygdala in fear conditioning measured with fear-potentiated startle in rats trained concurrently with auditory and visual conditioned stimuli. J Neurosci 15:2312-2327.

Corodimas KP, LeDoux JE (1995) Disruptive effects of posttraining perirhinal cortex lesions on conditioned fear: contributions of contextual cues. Behav Neurosci 109:613-619.

Cruikshank SJ, Edeline J-M, Weinberger NM (1992) Stimulation at a site of auditory-somatosensory convergence in the medial geniculate nucleus is an effective unconditioned stimulus for fear conditioning. Behav Neurosci 106:471-483.

Davis M (1992) The role of the amygdala in fear and anxiety. Annu Rev Neurosci 15:353-375.

Dudai Y (1996) Consolidation: fragility on the road to the engram. Neuron 17:367-370.

Ennaceur A, Aggleton JP (1997) The effects of neurotoxic lesions of the perirhinal cortex combined to fornix transection on object recognition memory in the rat. Behav Brain Res 88:181-193.

Fanselow MS, Kim JJ (1994) Acquisition of contextual pavlovian fear conditioning is blocked by application of an NMDA receptor antagonist D,L-2-amino-5-phosphonovaleric acid to the basolateral amygdala. Behav Neurosci 108:210-212.

Frankland PW, Cestari V, Filipkowski RK, McDonald RJ, Silva AJ (1998) The dorsal hippocampus is essential for context discrimination but not for contextual conditioning. Behav Neurosci 112:863-874.

Gaffan D (1994) Dissociated effects of perirhinal cortex ablation, fornix transection and amygdalectomy: evidence for multiple memory systems in the primate temporal lobe. Exp Brain Res 99:411-422.

Green EJ, McNaughton BL, Barnes CA (1990) Exploration-dependent modulation of evoked responses in fascia dentata: dissociation of motor, EEG, and sensory factors and evidence for a synaptic efficacy change. J Neurosci 10:1455-1471.
Helmstetter FJ (1992) Contribution of the amygdala to learning and performance of conditional fear. Physiol Behav 51:1271-1276.

Jarrell TW, Romanski LM, Gentile CG, McCabe PM, Schneiderman N (1986) Ibotenic acid lesions in the medial geniculate region prevent the acquisition of differential Pavlovian conditioning of bradycardia to acoustic stimuli in rabbits. Brain Res 382:199-203.

Kim JJ, Fanselow MS (1992) Modality-specific retrograde amnesia of fear. Science 256:675-677.

LeDoux JE, Sakaguchi A, Reis DJ (1983) Subcortical efferent projections of the medial geniculate nucleus mediate emotional responses conditioned to acoustic stimuli. J Neurosci 4:683-698.

LeDoux JE, Ruggiero DA, Reis DJ (1985) Projections to the subcortical forebrain from anatomically defined regions of the medial geniculate body in the rat. J Comp Neurol 242:182-213.

LeDoux JE, Iwata J, Pearl D, Reis DJ (1986) Disruption of auditory but not visual learning by destruction of intrinsic neurons in the rat medial geniculate body. Brain Res 371:395-399.

LeDoux JE, Ruggiero DA, Forest R, Stornetta R, Reis DJ (1987) Topographic organization of convergent projections to the thalamus from the inferior colliculus and spinal cord in the rat. J Comp Neurol 264:123-146.

Liu P, Bilkey DK (1998) Perirhinal cortex contributions to performance in the Morris water maze. Behav Neurosci 112:304-315.

Maren S (1998) Overtraining does not mitigate contextual fear conditioning deficits produced by neurotoxic lesions of the basolateral amygdala. J Neurosci 18:3088-3097.

Maren S, Fanselow MS (1995) Synaptic plasticity in the basolateral amygdala induced by hippocampal formation stimulation in vivo. J Neurosci 15:7548-7564.

Maren S, Fanselow MS (1996) The amygdala and fear conditioning: has the nut been cracked? Neuron 16:237-240.

Maren S, Aharonov G, Fanselow MS (1996) Retrograde abolition of conditional fear after excitotoxic lesions in the basolateral amygdala of rats: absence of a temporal gradient. Behav Neurosci 110:718-726.

McEchron MD, McCabe PM, Green EJ, Llabre MM, Schneiderman N (1995) Simultaneous single unit recording in the medial nucleus of the medial geniculate nucleus and amygdaloid central nucleus throughout habituation, acquisition, and extinction of the rabbit's classically conditioned heart rate. Brain Res 682:157-166.

McGaugh JL (1966) Time-dependent processes in memory storage. Science 153:1351-1358.

McGaugh JL, Cahill L, Parent MB, Meshes MH, Coleman-Mesches K, Salinas JA (1995) Involvement of the amygdala in the regulation of memory storage. In: Plasticity in the cerebral nervous system. Learning and memory (McGaugh JL, Bermudez-Rattoni F, Prado-Alcalà RA, eds), pp 17-39. Mahwah, NJ: Erlbaum.

McGaugh JL, Cahill L, Roozendaal B (1996) Involvement of the amygdala in memory storage: interaction with other brain systems. Proc Natl Acad Sci USA 93:13508-13514.

McKernan MG, Shinnick-Gallagher P (1997) Fear conditioning induces a lasting potentiation of synaptic currents in vitro. Nature 390:607-611.

McNish KA, Gewirtz JC, Davis M (1997) Evidence of contextual fear after lesions of the hippocampus: a disruption of freezing but not fear-potentiated startle. J Neurosci 17:9353-9360.

Meunier M, Bachevalier J, Mishkin M, Murray EA (1993) Effects on visual recognition of combined and separate ablations of the entorhinal and perirhinal cortex in rhesus monkeys. J Neurosci 13:5418-5432.

Morris RGM, Anderson E, Lynch GS, Baudry M (1986) Selective impairment of learning and blockade of long-term potentiation by an $N$-methyl-D-aspartate receptor antagonist, AP5. Nature 319:774-776.

Muller J, Corodimas KP, Fridel Z, LeDoux JE (1997) Functional inactivation of the lateral and basal nuclei of the amygdala by muscimol inf usion prevents fear conditioning to an explicit conditioned stimulus and to contextual stimuli. Behav Neurosci 111:683-691.

Nadel L, Moscovich M (1997) Memory consolidation, retrograde amnesia and the hippocampal complex. Curr Opin Neurobiol 7:217-227.

Nadel L, Willner J (1980) Context and conditioning: a place for space. Physiol Psychol 8:218-228.

Oler JA, Markus EJ (1998) Age-related deficits on the radial maze and in fear conditioning: hippocampal processing and consolidation. Hippocampus 8:402-415.

Otto T, Wolf D, Walsh TJ (1997) Combined lesions of perirhinal and entorhinal cortex impair rats' performance in two versions of the spatially guided radial-arm maze. Neurobiol Learn Mem 68:21-31.

Parent MB, McGaugh JL (1994) Posttraining infusion of lidocaine into 
the amygdala basolateral complex impairs retention of inhibitory avoidance training. Brain Res 661:97-103.

Paxinos G, Watson C (1986) The rat brain in stereotaxic coordinates. New York: Academic.

Phillips RG, LeDoux JE (1992) Differential contribution of amygdala and hippocampus to cued and contextual fear conditioning. Behav Neurosci 106:274-285.

Rogan MT, Staubli UV, LeDoux JE (1997) Fear conditioning induces associative long-term potentiation in the amygdala. Nature 390:604-607.

Romanski LM, LeDoux JE (1992) Equipotentiality of thalamoamygdala and thalamo-cortico-amygdala circuits in auditory fear conditioning. J Neurosci 12:4501-4509.

Rosen JB, Hitchcock JM, Miserendino MJD, Falls WA, Campeau S, Davis M (1992) Lesions of the perirhinal cortex but not of the frontal, medial prefrontal, visual, or insular cortex block fear-potentiated startle using a visual conditioned stimulus. J Neurosci 12:4624-4633.

Rudy JW, Morledge P (1994) Ontogeny of contextual fear conditioning in rats: implications for consolidation, infantile amnesia, and hippocampal system function. Behav Neurosci 108:227-234.

Sacchetti B, Ambrogi Lorenzini C, Baldi E, Tassoni G, Bucherelli C (1999) Memorization of contextual and CS conditioned fear response (freezing) in a one-trial acquisition paradigm. Arch Ital Biol 137:235-248.

Sutherland RJ, Arnold KA, Rodriguez AR (1987) Anterograde and retrograde effects on place memory after limbic or diencephalic damage. Neurosci Soc Abstr 13:297.

Suzuki WA (1996) The anatomy, physiology and functions of the perirhinal cortex. Curr Opin Neurobiol 6:179-186.

Wiig KA, Bilkey DK (1994) Perirhinal cortex lesions in rats disrupt performance in a spatial DNMS task. NeuroReport 5:1405-1408.

Wiig KA, Bilkey DK (1995) Lesions of rat perirhinal cortex exacerbate the memory deficit observed following damage to the fimbria-fornix. Behav Neurosci 109:620-630.

Winocur G (1997) Hippocampal lesions alter conditioning to conditional and contextual stimuli. Behav Brain Res 88:219-229.

Zola-Morgan S, Squire LR, Amaral DG (1989) Lesions of the amygdala that spare adjacent cortical regions do not impair memory or exacerbate the impairment following lesions of the hippocampal formation. J Neurosci 9:1922-1936.

Zhuravin IA, Bures J (1991) Extent of the tetrodotoxin induced blockade examined by pupillary paralysis elicited by intracerebral injection of the drug. Exp Brain Res 83:687-690. 